\title{
COMMENTARY
}

\section{Asking the right questions: the relationship between incident ventilator-associated pneumonia and mortality}

\author{
Michael J Lanspa ${ }^{1,2}$ and Samuel M Brown ${ }^{1,2, *}$ \\ See related research by Forel et al., http://ccforum.com/content/16/2/R65
}

\begin{abstract}
Whether ventilator-associated pneumonia is a manifestation of severity of illness or an independent cause of mortality in ventilator-dependent patients is not known. In this complex area, which cannot be readily subjected to randomized controlled trials, studies should focus on the underlying questions of relevance, how to improve care of ventilated patients.
\end{abstract}

In this issue of Critical Care, Forel and colleagues [1], in a substudy of the ACURASYS trial of neuromuscular blockade in patients with severe acute respiratory distress syndrome (ARDS) [2], explore the association between mortality and incident ventilator-associated pneumonia (VAP) in ARDS, a problem of causal inference that has remained unresolved despite multiple attempts to clarify the question [3]. Forel and colleagues' careful study, employing a rigorous definition of incident VAP [4] and multistate regression to attempt to control for the timedependence of VAP, is probably the best observational study of its kind on the topic. According to their analysis, VAP was not independently associated with mortality after controlling for severity of illness in a multi-state model.

This study is of excellent quality on many fronts. Ascertainment of VAP was rigorous and prospective, outcomes were established prospectively. Unlike many prior studies pertaining to VAP in ARDS patients [5-7], Forel and colleagues employed lung-protective ventilation strategies [8], which improves the signal-to-noise

\footnotetext{
*Correspondence: michael.lanspa@imail.org

${ }^{2}$ Division of Pulmonary and Critical Care Medicine, Intermountain Medical Center, Shock-Trauma Intensive Care Unit, 5121 S. Cottonwood Street, Murray, UT 84107, USA

Full list of author information is available at the end of the article
}

ratio and the likelihood of ascertaining actual relationships.

At the same time, most studies of the relationship between mortality and VAP [3,5-7], including the present one, suffer from some combination of length bias and time-dependent bias. In order to acquire VAP, a patient must survive on the ventilator for a period of time, probably somewhere between 4 and 12 days, and this time lag in susceptibility to VAP will vary from patient to patient $[5,9]$. The model Forel and colleagues employed does not fully overcome length- and time-dependent bias, as we depict in Figure 1a,b. Figure 1c depicts a more accurate multi-state model for this problem, but this non-biased schematic obfuscates the fact that 'VAPsusceptibility' is currently an essentially unmeasurable state. The fact that the authors' sensitivity analysis restricted to those patients surviving at least 9 days almost achieved statistical significance $(P=0.055)$, in the face of a small sample size, suggests the possibility that VAP is, in fact, independently associated with mortality. The fact that this extremely well designed study was unable to answer the question definitively suggests that this methodology has provided all that it can offer.

The limitations of observational methods raise the issue of which problems matter most about clinical outcomes in VAP. The purest methodology for determining whether VAP increases mortality in humans is unethical to the point of being criminal: instill bacteria directly into the trachea of a ventilated patient, as is standard in animal studies of pneumonia. But such an experiment is not only criminal, it is also scientifically pointless. Direct induction of pneumonia in ventilated patients is a bad idea, regardless of whether antibiotic therapy could avert a fatal outcome.

If the pure methodology for assessing the relationship between VAP and death is unethical and irrelevant, it is worth asking what questions matter most. With trends toward penalties for healthcare facilities based on VAP incidence, one important question is whether VAP rates 


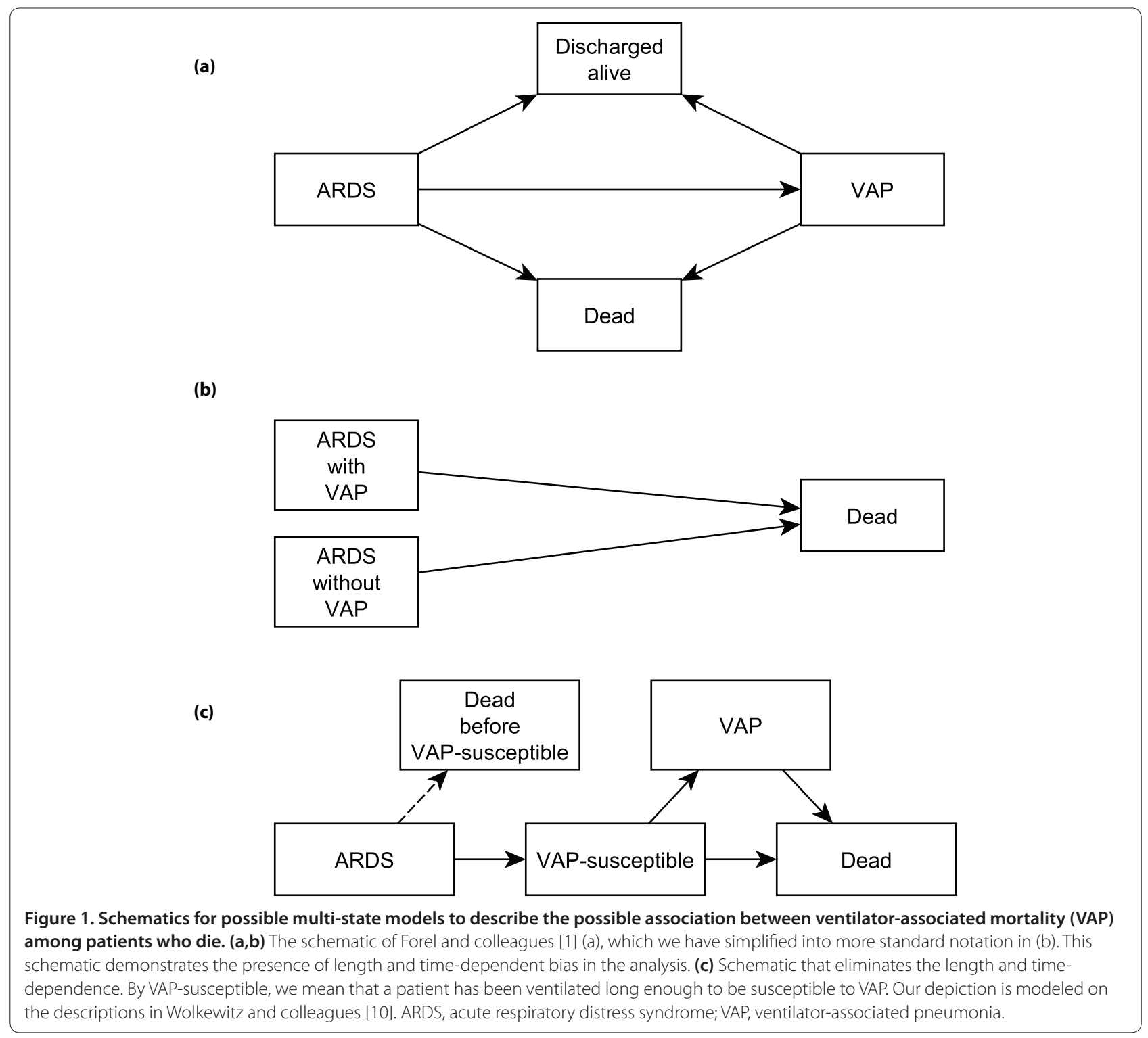

are surrogates for quality of clinical care. Recognizing that facilities with high early mortality rates may have lower VAP rates - an effect that could be compounded by early transition to comfort care in high-risk patients simple comparisons of VAP rates, even after standard severity-adjustment, may be highly misleading. A metric that incorporates process measures (for example, elevation of the head of the bed, oral care, possibly alimentary tract decontamination) and severity-adjusted mortality rates will almost certainly outperform even severity-adjusted VAP rates.

A more important question is whether interventions to improve care of patients with respiratory failure targeted at prevention or improved treatment of VAP will improve mortality. Such interventions will almost certainly need to be multi-factorial and multi-disciplinary. Studies of relevant interventions are urgently needed and should be supported by healthcare facilities and research-funding bodies. Equivocal findings from observational studies about associations between mortality and VAP should not diminish our enthusiasm for high-quality interventional trials aimed at improving outcomes for patients with ventilator-dependent respiratory failure and/or VAP.

\section{Abbreviations}

ARDS, acute respiratory distress syndrome; VAP, ventilator-associated pneumonia.

\section{Competing interests}

The authors declare that they have no competing interests.

\section{Author details}

'Division of Pulmonary and Critical Care Medicine, University of Utah School of Medicine, Salt Lake City, UT 84132, USA. ² Division of Pulmonary and Critical Care Medicine, Intermountain Medical Center, Shock-Trauma Intensive Care Unit, 5121 S. Cottonwood Street, Murray, UT 84107, USA. 
Published: 30 April 2012

\section{References}

1. Forel JM, Voillet F, Pulina D, Gaucouin A, Perrin G, Barrau K, Jaber S, Arnal JM, Fathallah M, Auquier P, Roch A, Azoulay E, Papazian L: Ventilator-associated pneumonia and ICU mortality in severe ARDS patients ventilated according to a lung-protective strategy. Crit Care 2012, 16:R65.

2. Papazian L, Forel JM, Gacouin A, Penot-Ragon C, Perrin G, Loundou A, Jaber S, Arnal JM, Perez D, Seghboyan JM, Constantin JM, Courant P, Lefrant JY, Guérin C, Prat G, Morange S, Roch A; ACURASYS Study Investigators: Neuromuscular blockers in early acute respiratory distress syndrome. N Engl I Med 2010, 363:1107-1116.

3. Melsen WG, Rovers MM, Bonten MJ: Ventilator-associated pneumonia and mortality: a systematic review of observational studies. Crit Care Med 2009, 37:2709-2718

4. Craven DE, Hjalmarson Kl: Ventilator-associated tracheobronchitis and pneumonia: thinking outside the box. Clin Infect Dis 2010, 51 Suppl 1:S59-66.

5. Markowicz P, Wolff M, Djedaiini K, Cohen Y, Chastre J, Delclaux C, Merrer J, Herman B, Veber B, Fontaine A, Dreyfuss D: Multicenter prospective study of ventilator-associated pneumonia during acute respiratory distress syndrome. Incidence, prognosis, and risk factors. ARDS Study Group. Am J Respir Crit Care Med 2000, 161:1942-1948.
6. Sutherland KR, Steinberg KP, Maunder RJ, Milberg JA, Allen DL, Hudson LD: Pulmonary infection during the acute respiratory distress syndrome. Am $J$ Respir Crit Care Med 1995, 152:550-556.

7. Meduri GU, Reddy RC, Stanley T, El-Zeky F: Pneumonia in acute respiratory distress syndrome. A prospective evaluation of bilateral bronchoscopic sampling. Am J Respir Crit Care Med 1998, 158:870-875.

8. Ventilation with lower tidal volumes as compared with traditional tidal volumes for acute lung injury and the acute respiratory distress syndrome. The Acute Respiratory Distress Syndrome Network. N Engl J Med 2000, 342:1301-1308.

9. Cook DJ, Walter SD, Cook RJ, Griffith LE, Guyatt GH, Leasa D, Jaeschke RZ, Brun-Buisson C: Incidence of and risk factors for ventilator-associated pneumonia in critically ill patients. Ann Intern Med 1998, 129:433-440.

10. Wolkewitz M, Allignol A, Schumacher M, Beyersmann J: Two pitfalls in survival analyses of time-dependent exposure: a case study in a cohort of oscar nominees. Am Stat 2010, 64:205-211

\section{doi:10.1186/cc11308}

Cite this article as: Lanspa MJ, Brown SM: Asking the right questions: the relationship between incident ventilator-associated pneumonia and mortality. Critical Care 2012, 16:123. 